\title{
Soil management effect on soil penetration resistance in the vineyard
}

\author{
Pietro Catania, ${ }^{1}$ Mariangela Vallone, ${ }^{1}$ Felice Pipitone, ${ }^{1}$ Gioacchino Francesco Argento, ${ }^{1}$ \\ Giuseppe Spartà, ${ }^{2}$ Vito Armando Laudicina ${ }^{1}$ \\ ${ }^{1}$ University of Palermo, Dipartimento di Scienze Agrarie e Forestali, Palermo, Italy; ${ }^{2}$ Assessorato \\ Regionale Risorse Agricole e Alimentari, Palermo, Italy
}

\begin{abstract}
In environments characterized by steep slopes or arranged in terraces, among the shallow tillage systems, rototilling is extensively used. However, the effect of the repeated use of rototilling has a considerable influence on soil characteristics; it appears finely powdered, soft and without structure. In order to limit these inconveniences, an innovative self-propelled machine equipped with working tools as a spade, to be used in steep slopes or arranged in terraces areas, was designed by the Mechanics Section of the SAF (Scienze Agrarie e Forestali) Department of the University of Palermo in cooperation with Agrotec company, Padua, Italy. The aim of this study is to compare the effects of three machines for shallow tillage: a chisel plough (CP), a rototilling (RT) and a spading machine (SM) on penetration resistance in semi-arid environments of the Mediterranean basin. No tillage was also included. Penetration resistance (PR) was surveyed for all the treatments to a depth of $300 \mathrm{~mm}$ with an electronic dynamometer. The treatments consisted in the execution of a shallow tillage to a depth of $150 \mathrm{~mm}$. SP treatment allowed us to obtain PR lower values throughout the tillage profile than RT, CP and NT. It follows that the type of machine used influences soil PR, and then the soil water storage capacity, key factor for the agricultural productions in semi-arid environments as in Sicily.
\end{abstract}

Correspondence: Pietro Catania, University of Palermo. Dipartimento di Scienze Agrarie e Forestali, Viale Delle Scienze Edificio 4, 90128 Palermo, Italy.

Tel. +39.91.23865608.

E-mail: pietro.catania@unipa.it

Key words: penetration resistance, spading machine, tillage

Contributions: the authors contributed equally.

Conflict of interests: the authors declare no potential conflict of interests.

Conference presentation: part of this paper was presented at the 10th Italian Conference AIIA (Associazione Italiana di Ingegneria Agraria), 2013 September 8-12, Viterbo, Italy.

(C) Copyright P. Catania et al., 2013

Licensee PAGEPress, Italy

Journal of Agricultural Engineering 2013; XLIV(s2):e68

doi:10.4081/jae.2013.s2.e68

This article is distributed under the terms of the Creative Commons Attribution Noncommercial License (by-nc 3.0) which permits any noncommercial use, distribution, and reproduction in any medium, provided the original author(s) and source are credited.

\section{Introduction}

In environments characterized by steep slopes or arranged in terraces, among the shallow tillage systems, rototilling is extensively used. This is because this machine allows in one step to clean the soil from weeds, to obtain it well crumbled and in excellent condition for the subsequent operations. It can also be adjusted to enhance the tractor coupling and optimize the balance between energy cost and quality of work (Pezzi, 2005, Hendrick, 1980).

However, the effect of the repeated use of rototilling has a considerable influence on soil characteristics; it appears finely powdered, soft and without structure.

This phenomenon is even more favored in environments with volcanic soils (island of Pantelleria, mount Etna, island of Salina, etc.) with predominantly pyroclastic deposits, characterized by compositional and textural heterogeneity, high porosity and poor mechanical strength properties. Therefore, these soils have an high degree of vulnerability and are closely prone to surface instability and erosion (Vallone et al., 2007). Soil pulverization causes a lack in soil structure and this immediately causes the loss of its storage capacity of water reservoir and, consequently, of its fertility.

In order to limit these inconveniences, an innovative self-propelled machine equipped with working tools as a spade, to be used in steep slopes or arranged in terraces areas, was designed by the Mechanics Section of the SAF (Scienze Agrarie e Forestali) Department of the University of Palermo in cooperation with Agrotec company, Padua, Italy.

The aim of this study is to compare the effects of three machines for shallow tillage: a chisel plough (CP), a rototilling (RT) and a spading machine (SM) on penetration resistance in semi-arid environments of the Mediterranean basin. No tillage was also included.

\section{Materials and methods}

The innovative spading machine (SM) is self-propelled and is equipped with five working tools of the spade-type with two blows each moved by the hydraulic circuit of the machine. The rototilling (RT) has got eight elements, inserted into the central rotor, driven by the PTO of the tractor. The chisel plough (CP) has got five chisels. The machines used in the tests are shown in Fig.1. Four treatments were realized, including no tillage.

The tests were performed in the spring of 2012 (April-May) on a sandy clay loam soil. The experimental plot was inside the Faculty of Agriculture of the University of Palermo, it was covered in vineyard and located at $38^{\circ} 06^{\prime} \mathrm{N}$ and $13^{\circ} 20^{\prime} \mathrm{E}, 48 \mathrm{~m}$ above sea level. The area's climate is mild with rainfall largely concentrated in the winter.

Penetration resistance (PR) was surveyed for all the treatments to a depth of $300 \mathrm{~mm}$ with an electronic dynamometer (IMADA, DPS 5R USA) detecting forces up to $500 \mathrm{~N}$, connected to a mechanical stand 
(IMADA MX2-500N - L). The measured values, recorded by the software IMADA ZP Recorder, were downloaded to a spreadsheet for further processing. The penetrometer used for the tests was equipped with a cone having $10 \mathrm{~mm}$ diameter base; it was mounted to the dynamometer through a $6 \mathrm{~mm}$ diameter steel bar (Fig. 2).

The treatments consisted in the execution of a shallow tillage to a depth of $150 \mathrm{~mm}$ using the three different machines; three blocks were located inside the experimental plot and divided into four subplots where the treatments were randomly performed. Penetration tests were performed soon after tillage at the time called T1 on the four treatments (SP, RT, CP and NT) till $300 \mathrm{~mm}$ depth. Penetration resistance was also evaluated 30 days after tillage at the time called T2. Statistical analysis was performed using Statgraphics Centurion by Statpoint inc., USA.

\section{Results}

Figure 3 shows penetration resistance soon after tillage (T1) for the four treatments till $300 \mathrm{~mm}$ depth.
The lowest PR values were obtained in SM treatment, then RT and CP and lastly NT. Note that, till $200 \mathrm{~mm}$ depth, PR values at 75, 100, 150 and $200 \mathrm{~mm}$ depth in SM treatment show statistically significant differences respect to the other treatments at the same depths. In particular, note that these differences were obtained for a layer corresponding to $50 \%$ of that entirely tilled. At the depth of $75 \mathrm{~mm}$, the average values obtained by SM are lower by about $62 \%$ than those of RT, $74 \%$ of CP and $80 \%$ of NT. At the depth of $100 \mathrm{~mm}$ the average values obtained by SM are lower by about $74 \%$ than those of RT, $77 \%$ of CP and $83 \%$ of NT. At the depth of $150 \mathrm{~mm}$, the average PR values for SM are lower by about $52 \%$ of RT, $70 \%$ of CP and $58 \%$ of NT.

Penetration resistance data 30 days after tillage (T2) for the four treatments till $300 \mathrm{~mm}$ depth are shown in Figure 4 . It comes out that thirty days after tillage there is an increase in the value of PR in all the treatments. SM treatment gave PR average values lower than the others with statistically significant differences in the soil layer between 50 and $110 \mathrm{~mm}$, equal to $40 \%$ of the tilled soil.

In particular, note that at the depth of $75 \mathrm{~mm}$, the average values obtained by SM are lower by about 77\% than those of RT, $64 \%$ of CP and $80 \%$ of NT. At the depth of $100 \mathrm{~mm}$ the average values obtained by SM

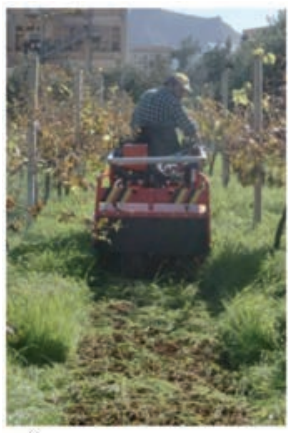

a)

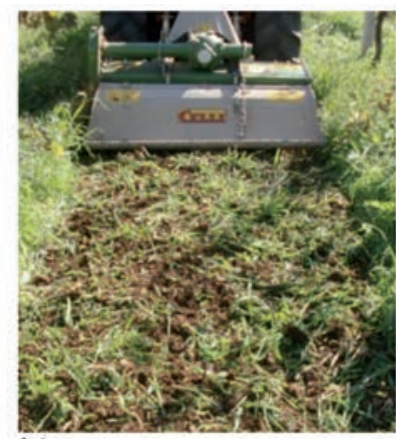

b)

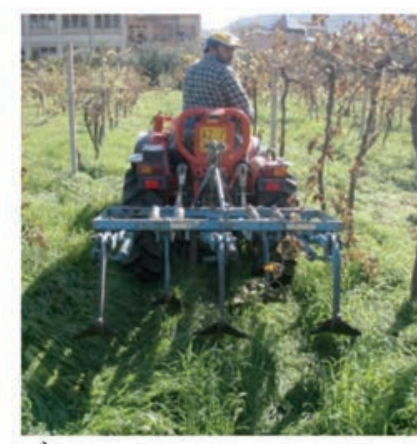

c)

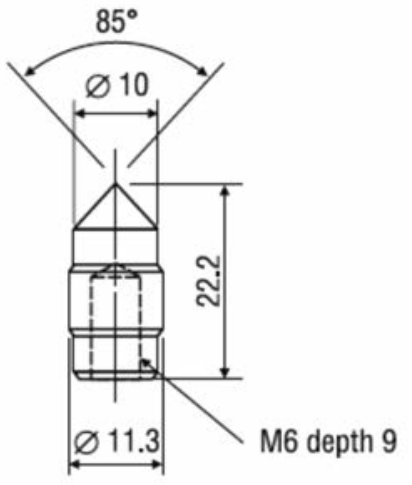

Figure 2. Cone penetrometer section used to measure penetration resistance. plough (CP).

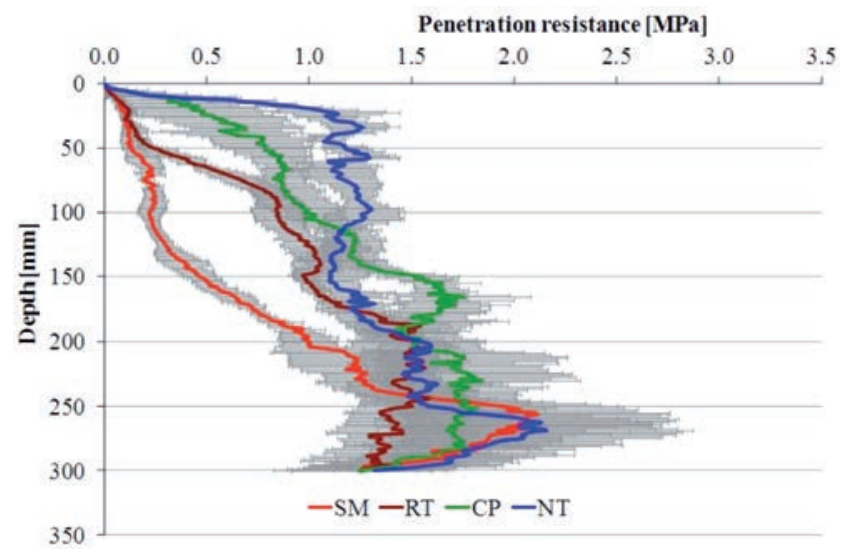

Figure 3. Penetration resistance for Spading Machine (SM), Rototilling (RT), Chisel Plough (CP) and No Tillage (NT) treatments soon after tillage (data are reported as means \pm standard deviations of the three replicates).

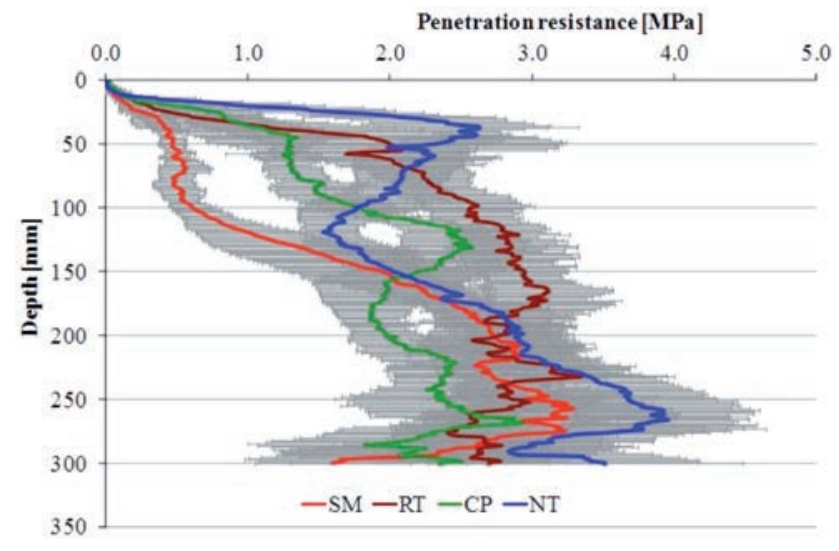

Figure 4. Penetration resistance for Spading Machine (SM), Rototilling (RT), Chisel Plough (CP) and No Tillage (NT) treatments 30 days after tillage (data are reported as means \pm standard deviations of the three replicates). 

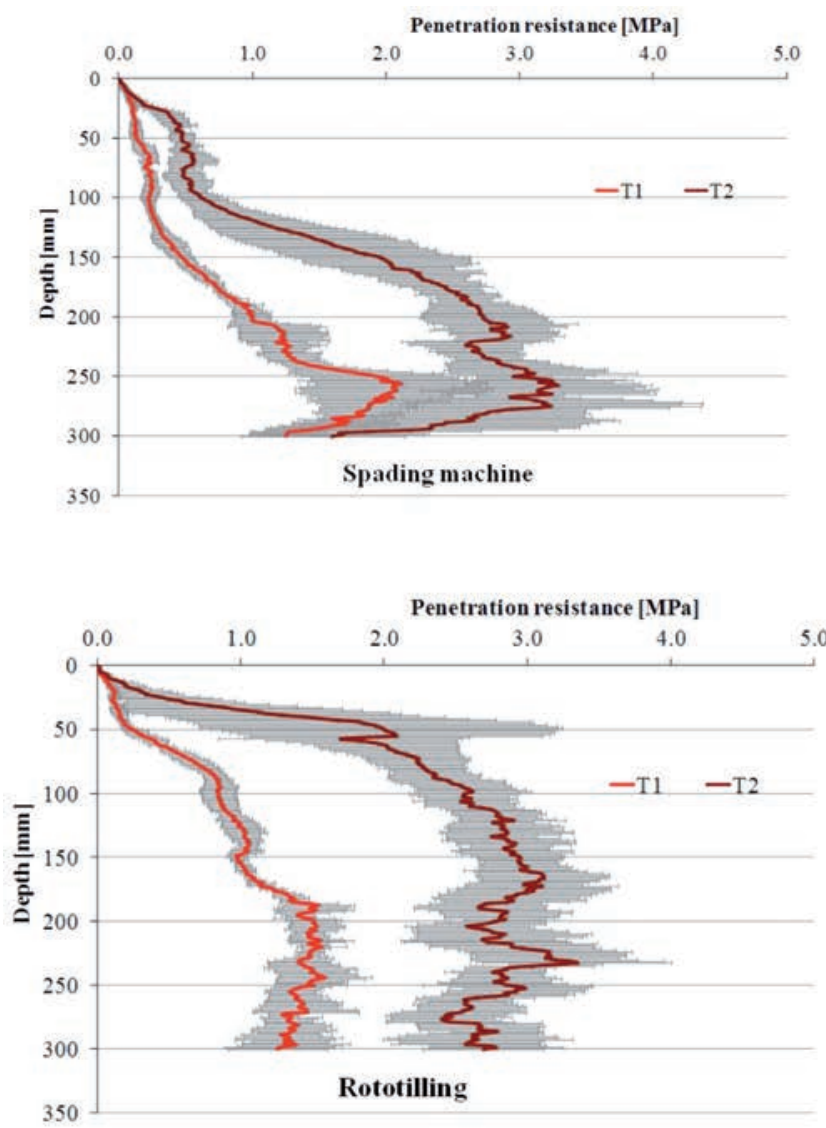
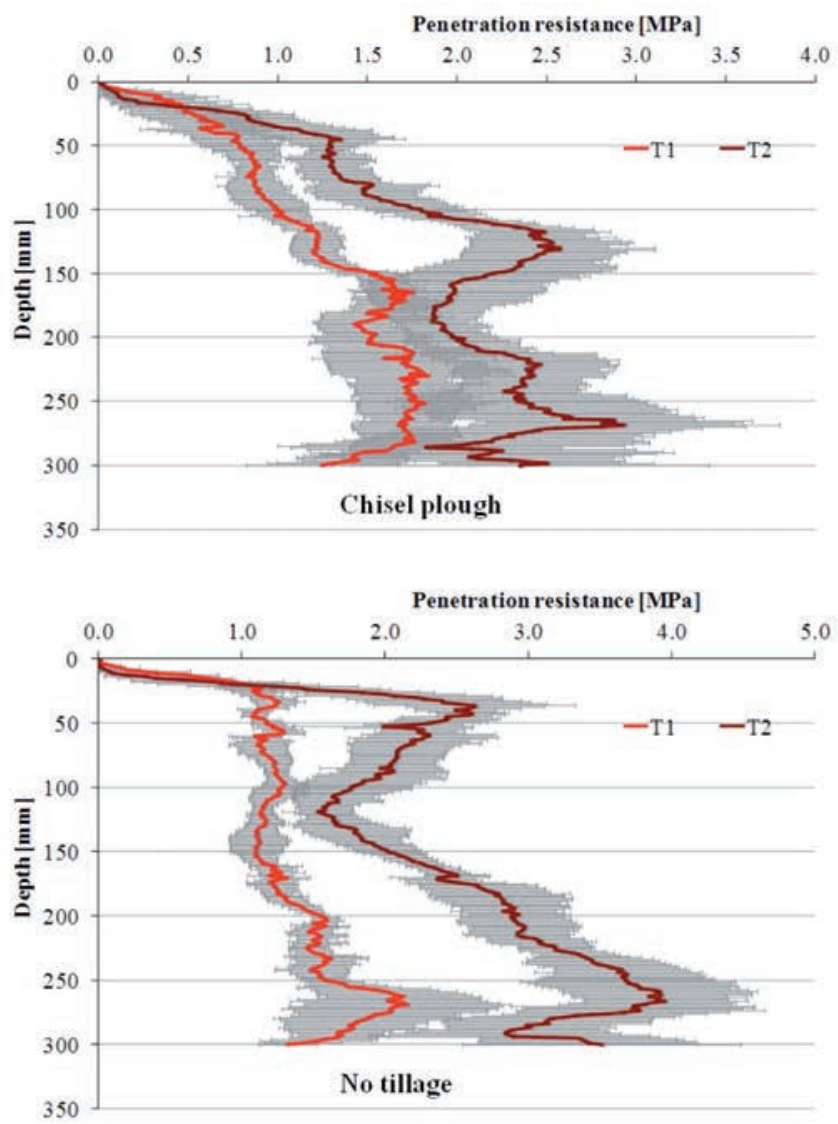

Figure 5. Penetration resistance for Spading Machine (SM), Rototilling (RT), Chisel Plough (CP) and No Tillage (NT) treatments soon after (T1) and 30 days after tillage (T2)(data are reported as means \pm standard deviations of the three replicates).

are lower by about $76 \%$ than those of RT, $66 \%$ of CP and $65 \%$ of NT.

Finally, comparing PR values in the four treatments, there are not statistically significant differences.

In Figure 5 we report the penetration resistance data collected individually in the four treatments in the two periods, immediately after tillage (T1) and thirty days after (T2).

Comparing the PR mean values obtained immediately after tillage (T1) and thirty days after it (T2) it comes out that RT is the treatment that undergoes a significant increase. The PR average values, in fact increase, with statistically significant differences between T1 and T2, of about $1.75 \mathrm{MPa}$ at $50 \mathrm{~mm}$ depth, of about $1.71 \mathrm{MPa}$ at $100 \mathrm{~mm}$ depth and of about $1.97 \mathrm{MPa}$ at $150 \mathrm{~mm}$ depth. MS treatment thirty days after tillage, shows PR average values higher by about $0.34 \mathrm{MPa}$ at $50 \mathrm{~mm}$ depth, by about $0.39 \mathrm{MPa}$ at a depth of $100 \mathrm{~mm}$ and about $1.49 \mathrm{MPa}$ at $150 \mathrm{~mm}$ depth with statistically significant differences between $\mathrm{T} 1$ and T2. CP and NT treatments show PR increases less considerable than the other.

\section{Conclusions}

The study was aimed at comparing the effects of three machines for shallow tillage: a chisel plough (CP), a rototilling (RT) and a spading machine (SM) on penetration resistance in a semi-arid environment of the Mediterranean basin. No tillage was also included.

SP treatment allowed us to obtain PR lower values throughout the tillage profile than RT, CP and NT. As regards the PR values obtained along the soil profile between 0 and $150 \mathrm{~mm}$, it appears that:

- $\quad$ in SP treatment PR does not exceed $2 \mathrm{MPa}$ immediately after and 30 days after tillage in the whole layer interested in tillage;

- in RT treatment PR reaches $3 \mathrm{MPa}$ at about $150 \mathrm{~mm}$ depth 30 days after tillage;

- $\quad$ in CP treatment PR reaches $2.5 \mathrm{MPa}$ at about $150 \mathrm{~mm}$ depth 30 days after tillage;

- $\quad$ in NT treatment PR reaches 2.5 MPa in the first $50 \mathrm{~mm}$ of depth 30 days after tillage.

It follows that the type of machine used influences soil PR, and then the soil water storage capacity, key factor for the agricultural productions in semi-arid environments as in Sicily.

\section{References}

Bachmann J., Contreras K., Hartge K.H., MacDonald R. 2006. Comparison of soil strength data obtained in situ with penetrometer and with vane shear test. Soil \& Tillage Research, 87, 112118.

Hendrick J.G., 1980. A powered rotary chisel. Transactions of the ASAE, 1349-1352.

Lopez M.V., Arrue J.L., Sanchez-Giron V. 1996. A comparison between seasonal changes in soil water storage and penetration resi stance under conventional and conservation tillage systems in Aragon. 
Soil \& Tillage Research, 37, 251-271.

Pezzi F., 2005. Traditional and new deep soil tillage techniques in Italy. Transactions of the ASAE, 48(1), 13-17.

Sandri R., Anken T., Hilfiker T., Sartori L., Bollhalder H. 1998. Comparison of methods for determining cloddiness in seedbed preparation. Soil \& Tillage Research, 45, 75-90.

Singh B., Malhi S.S. 2006. Response of soil physical properties to tillage and residue management on two soils in a cool temperate environment. Soil \& Tillage Research, 85, 143-153.

Vallone M., Catania P., Pipitone F. Carrara M., 2007. Analisi delle modalità di gestione dei suoli di Pantelleria al fine di preservarne la fertilità - Atti del Convegno Nazionale AIIA 2007: Tecnologie innovative nelle filiere: orticola, vitivinicola e olivicolo-olearia, 5-7 Sept, Pisa e Volterra, Italy, II, 44-47. 